\title{
GREETING AND MEETING: VOCAL INTERACTIONS AND USE OF SIGNATURE WHISTLES IN BOTTLENOSE DOLPHINS (TURSIOPS TRUNCATUS) DURING AN INTRODUCTION
}

\author{
Heidi Lyn and Megan Broadway \\ *Corresponding Author: Heidi.lyn@usm.edu \\ ${ }^{1}$ Department of Psychology, University of Southern Mississippi, Long Beach, MS 39560
}

Bottlenose dolphins are the focus of a great deal of mythology that casts all dolphins and whales as on par or exceeding humans in their intelligence and communicative abilities (Gregg, 2013). Experiments with artificial language systems have shown that dolphins can attach meaning to symbols (Herman, 1987) and can follow arbitrary ordering rules (Herman, Kuczaj, \& Holder, 1993), much like human syntax, but have failed to find elements that suggest the complexity of human language (Kako, 1999). However, dolphins have been found to utilize a rare call type that has only been found in humans, some parrots, and dolphins (Balsby \& Bradbury, 2009; Janik, Sayigh, \& Wells, 2006; Wanker, Sugama, \& Prinage, 2005) - a unique signal that may be used to identify individuals - the signature whistle (Caldwell \& Caldwell, 1965).

In the years since they were first identified, it has become relatively well established that signature whistles are utilized in much the same way as contact calls, except they also carry identity information (Janik et al., 2006). One study even showed that when separate groups of dolphins encountered each other in the wild, an increase in signature whistling was correlated with the likelihood that those groups would then travel together (Quick \& Janik, 2012). This pattern suggested that signature whistles may be used as greeting communications, potentially soothing fraught initial interactions.

Our study questioned whether this pattern of behavior would be observed in a captive environment. Because dolphin introductions in captive environments occur in a controlled setting, researchers can monitor the production of signature whistles by individuals in this context. We recorded vocal interactions as a new individual, a juvenile male, was introduced to a group of two resident dolphins, 
an adult male and female. As observed in the wild, we expected to record an increase in signature whistling at the onset of the introduction.

Instead, we found more individualistic reactions. The new individual, who had been signature whistling constantly during his quarantine, ceased signature whistling immediately upon introduction $\left(X^{2}(\mathrm{df}=3, N=475)=162.095, p<\right.$ .001 , Cohen's $w=.58$ ) and the adult male' production of signature whistles did not change. The adult female was the only dolphin to meet our expectation of increased signature whistle production $\left(X^{2}(\mathrm{df}=3, N=26)=16.15, p=.001\right.$, Cohen's $w=.79$ ) (Table 1).

Table 1. Whistle rates per hour for each dolphins' signature whistle (SW) and all other whistles during each phase of the study.

\begin{tabular}{lcccc}
\hline & $\begin{array}{c}\text { Adult } \\
\text { Female's SW }\end{array}$ & $\begin{array}{c}\text { Adult } \\
\text { Male's SW }\end{array}$ & $\begin{array}{c}\text { New } \\
\text { Dolphin's SW }\end{array}$ & $\begin{array}{c}\text { Other } \\
\text { Whistles }\end{array}$ \\
\hline Baseline & 0 & 3 & 173 & 46 \\
Introduction Day & 11 & 5 & 2 & 32 \\
Post-Introduction & 11 & 3 & 57 & 55 \\
Follow-up & 10 & 8 & 282 & 85 \\
Total & 33 & 19 & 514 & 218 \\
\hline
\end{tabular}

Several possibilities exist for this pattern of whistling. It is possible that the artificial nature of the introduction changed the dolphins' responses. However, more likely, the newcomer's youth and propensity to whistle less when under stress led to his reaction. The adult male's underwhelming response to the new dolphin was unexpected in that most male-male introductions that have been described entail aggressive responses. It is possible that, due to difficulties in detection, the adult male's whistle rate may have been underestimated, however, he also failed to show interest behaviorally, suggesting a true lack of interest. The adult female, consistent with her increased signature whistle production, interacted with the newcomer almost immediately, showing the typical response of dolphins encountering a new conspecific and supporting the hypothesis that signature whistles may be used as a greeting behavior.

This reaction to an introduction is an intriguing glimpse into the function of signature whistles during initial encounters. Future work should allow researchers to continue to delineate the function and use of this unique form of communication. As one of the only species to utilize labels akin to human names, this may elucidate the evolutionary path to flexible, meaningful, referential communication systems. 


\section{References}

Balsby, T. J. S., \& Bradbury, J. W. (2009). Vocal matching by orange-fronted conures (Aratinga canicularis). Behavioural Processes, 82(2), 133-9. https://doi.org/10.1016/j.beproc.2009.05.005

Caldwell, M. C., \& Caldwell, D. K. (1965). Individualized Whistle Contours in Bottle-nosed Dolphins (Tursiops truncatus). Nature, 207(4995), 434-435. https://doi.org/10.1038/207434a0

Gregg, J. D. (2013). Are Dolphins Really Smart? Oxford, UK: Oxford University Press.

Herman, L. M. (1987). Receptive competencies of language-trained animals. Advances in the Study of Behavior, 17, 1-60.

Herman, L. M., Kuczaj, S. A., \& Holder, M. D. (1993). Responses to anomalous gestural sequences by a language-trained dolphin: evidence for processing of semantic relations and syntactic information. Journal of Experimental Psychology: General, 122(2), 184-194.

Janik, V. M., Sayigh, L. S., \& Wells, R. S. (2006). Signature whistle shape conveys identity information to bottlenose dolphins. Proceedings of the National Acadamy of Sciences, 103, 8293-8297.

Kako, E. (1999). Elements of syntax in the systems of three language-trained animals. Animal Learning and Behavior, 27(1), 1-14.

Quick, N. J., \& Janik, V. M. (2012). Bottlenose dolphins exchange signature whistles when meeting at sea. Proceedings of the Royal Society Biological Sciences Series B, 279(1738), 2539-2545. Retrieved from http://lynx.lib.usm.edu:2048/login?url=http://search.ebscohost.com/login.a spx?direct $=$ true $\& d b=$ bxh\&AN $=$ BACD201200325753\&site $=$ ehost-live

Wanker, R., Sugama, Y., \& Prinage, S. (2005). Vocal labelling of family members in spectacled parrotlets, Forpus conspicillatus. Animal Behaviour, 70(1), 111-118. https://doi.org/10.1016/j.anbehav.2004.09.022 